\title{
ESTIMATING THERMAL INERTIA AND TEMPERATURE DISTRIBUTION CONSISTENT WITH MONITORED DATA FROM A RAILWAY BRIDGE
}

\author{
Fabio Casciati ${ }^{1}$, Sara Casciati ${ }^{2}$, Lucia Faravelli ${ }^{1}$, Daniele Bortoluzzi ${ }^{1}$ and Thomas B. $^{2}$ \\ Messervey $^{3}$ \\ ${ }^{1}$ Department of Civil Engineering and Architecture, University of Pavia \\ Via Ferrata 1, 27100 Pavia, Italy \\ e-mail: fabio@dipmec.unipv.it
}
e-mail: saracasciati@msn.com
${ }^{3} \mathrm{R} 2 \mathrm{M}$ Solution srl
Via Monte Sant'Agata 16, 95100 Catania, Italy
thomas.messervey@r2msolution.com

${ }^{2}$ Dept. DICA, Dipartimento di Ingegneria Civile e Ambientale, School of Architecture, University of Catania at Siracusa, Piazza Federico di Svevia, 96100 Siracusa, Tel.: (+39) 3385953658

Keywords:, FBG sensors, Monitoring, Railways Bridge, Temperature.

\begin{abstract}
This paper proposes a sequence of analyses allowing the designer to quantify the changes in the structural response due to the temperature variation. This is illustrated for a case study on a railway bridge. The SHM (Structural Health Monitoring) system installed on the bridge consists of Fiber Bragg Grating (FBG) sensors. A numerical model of the bridge was created. The plot of the daily variation of the vertical displacement of a node, when numerically computed for a temperature field interpolating the readings of the temperature sensors, shows a curve similar to the recorded history plot, but the latter one is delayed. This delay is due to both the thermal inertia of the deck, the reinforced concrete of the superstructure, and the actual temperature distribution across and along the deck. Thus, a refined study of the temperature time histories was conducted by a suitable thermo-mechanical model driven by the temperatures measured at the sensor locations. The obtained field of temperature is then used as input for a stress-strain analysis. The resulting displacements are eventually compared with the measured values. Using a first set of data, the numerical model parameters are calibrated, while a second set of data is used for a validation of the whole procedure.
\end{abstract}




\section{INTRODUCTION}

In Structural Monitoring one collects data on the kinematics of the structural response, but these readings are strictly correlated with the temporal and spatial distribution of the temperature. It is a rule of thumb to associate temperature sensors to the units detecting the mechanical performance of the structural system [1-3]. Nevertheless, these temperature sensors are only covering a few points around the structure and this obliges one to find a way to model the spatial variability of the temperature. Furthermore, a virtual laboratory approach, i.e., a tool aiming at simulating numerically the behavior detected by the sensors, requires the availability of initial conditions of temperature even inside the structural elements.

The first aspect is well documented in the literature. Among others, in the book [4], one finds on page 59 a reconstruction of the temperature in the upper side and in the lower side of a bridge deck plotted together with the measured environment temperature.

Another study is reported in [5], where a further plot of recorded data is provided confirming a significant daily peak in the upper side of the deck, a lower peak for the lower side of the deck and valleys of the two plots at the values of the ambient temperature.

In this paper, the authors start from the standard situation of having collected data of both temperature and displacement, adopt a finite-element numerical model of the structural system and investigate the possibility of reconstructing the actual temperature field from the available data, so that the computed displacements match the recorded values.

\section{GOVERNING RELATIONS}

Following [6], a finite element model is created in Mentat [7-8] based on the available information on the bridge design and dimensional/sectional properties.

The boundary conditions are assigned as temperature time histories, moving from initial conditions which should be assigned on the boundary surface of the deck as well as at the internal points.

The following notations are introduced:

- $\quad B$ denotes the deck body;

- $\partial B$ denotes the external surface of the deck body which can be partitioned in:

- $\partial B_{1}$, i.e., the lateral surface of the deck, exposed to the air temperature variations;

- $\quad \partial B_{2}$, i.e., the end surfaces of the deck;

- $\quad \partial B_{3}$, i.e., the deck surface at the support location;

- $\Theta(x, y, z)$ denotes the temperature field;

- $u(x, y, z)$ denotes the displacement field. In any point the displacement should be a vector, but attention is focused here on the vertical component which is supposed to be measured by sensors at $M$ locations.

The thermo-mechanical problem, then, can be formulated as follows: at any instant of time $t$, find the displacement field $u$ resulting from a temperature variation accounting for the support settlement

$$
u(x, y, z \mid t)=F_{A}\left(\Theta(x, y, z \mid t), \Theta(x, y, z \mid t=0), u(x, y, z \mid t=0), u\left(\partial B_{3} \mid t\right)\right.
$$

Such a problem, however, cannot be directly approached since the temperature field at any time $t$ is ignored. One only knows the time evolution of the temperature in a small number of points, say $N$.

Thus the true problem becomes: 


$$
\begin{aligned}
& \Theta(x, y, z \mid t)=F_{B}\left(u\left(x_{i}, y_{i}, z_{i} \mid t\right) i=1, \ldots, M ;\right. \\
& \quad \Theta\left(x_{j}, y_{j}, z_{j} \mid t\right) j=1, \ldots, N \mid \Theta(x, y, z \mid t=0), u(u, y, z \mid t=0), u(\partial B 3 \mid t)
\end{aligned}
$$

but the available information does not cover all the degrees of freedom. Heuristic models must be introduced to cover the ignored quantities. In particular one assumes that:

$$
\begin{gathered}
\left.\Theta(x, y, z \in B \mid t)=F_{C}\left(\Theta\left(x, y, z \in \partial B_{1}, \partial B_{2}\right) \text { constant along } t+\Delta t\right)\right) \\
\Theta\left(x, y, z \in \partial B_{1}, \partial B_{2}\right)=F_{D}\left(\Theta\left(x_{j}, y_{j}, z_{j} \mid t\right) j=1, \ldots, N\right)
\end{gathered}
$$

Equation (4) assumes that one can extrapolate from the knowledge of the temperature in a few point the temperature on the whole lateral surface. Equation (3) expresses that from the knowledge of the temperature on the whole lateral surface, the temperature field at regime can be computed and it is independent from the initial conditions for $\Delta t$ sufficiently long.

\section{THE ROLE OF THERMAL INERTIA}

One neglects first Eq. (4), which mainly means to work at the time $t_{w}$ during the day that sees the upper deck and the lower deck to show the same value of temperature.

\subsection{Thermal inertia}

In Equation (3) the length of the time interval depends on the thermal inertia, which is here introduced as the system property which determines the decay from the initial conditions to the stationary one for the thermo-elastic problem. The first step, discussed in this section, is to check how this phenomenon affects the temperature measurement time-stepping.

With reference to a given rectangular geometry, which will be illustrated when the application is introduced in next section, and for a given day the following analysis is developed. From the uniform temperature of $292.9^{\circ} \mathrm{K}$ assigned to all nodes of a finite element model (initial condition), the four corner areas, where the temperature sensors are located, should be driven to the temperature read at time $t_{w}$, each different from the others. Since the driving temperature has to be assigned over the whole external surface (lateral, lower, upper and ends), the simple partition scheme in Figure 1 was adopted. In this way a sort of an external "thermal coat" is assigned all around the surface of the deck (boundary condition).

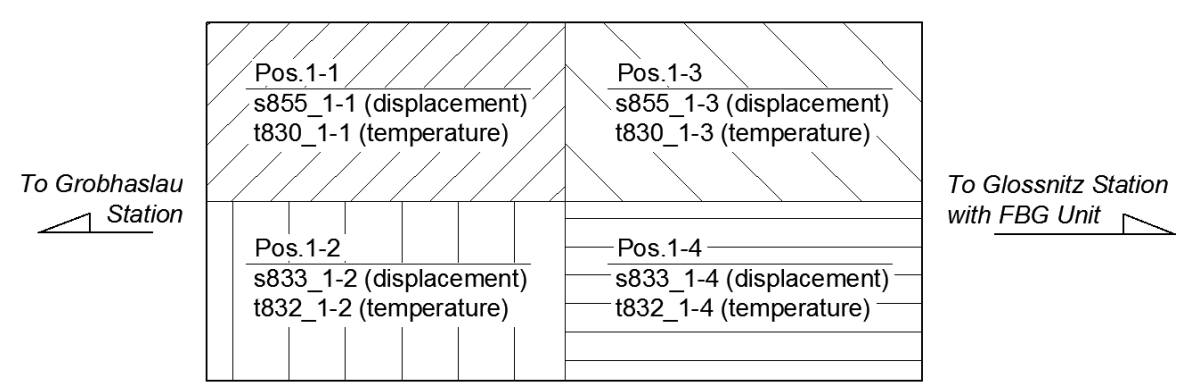

Figure 1. Zones of the deck of equal lateral surface temperature (view from above).

Once the boundary conditions are assigned a dynamic transient analysis was conducted. Two representative transversal sections of the deck were selected: the section in the middle of the support area, and the mid-span section. Figures from 2 to 4 summarize the distribution of the temperature at three different time steps: after $3840 \mathrm{sec}$ (nearly $1 \mathrm{~h}$ ), after $86400 \mathrm{sec}$ (nearly 1 day) and after $240000 \mathrm{sec}$ (nearly 3 days), respectively. 


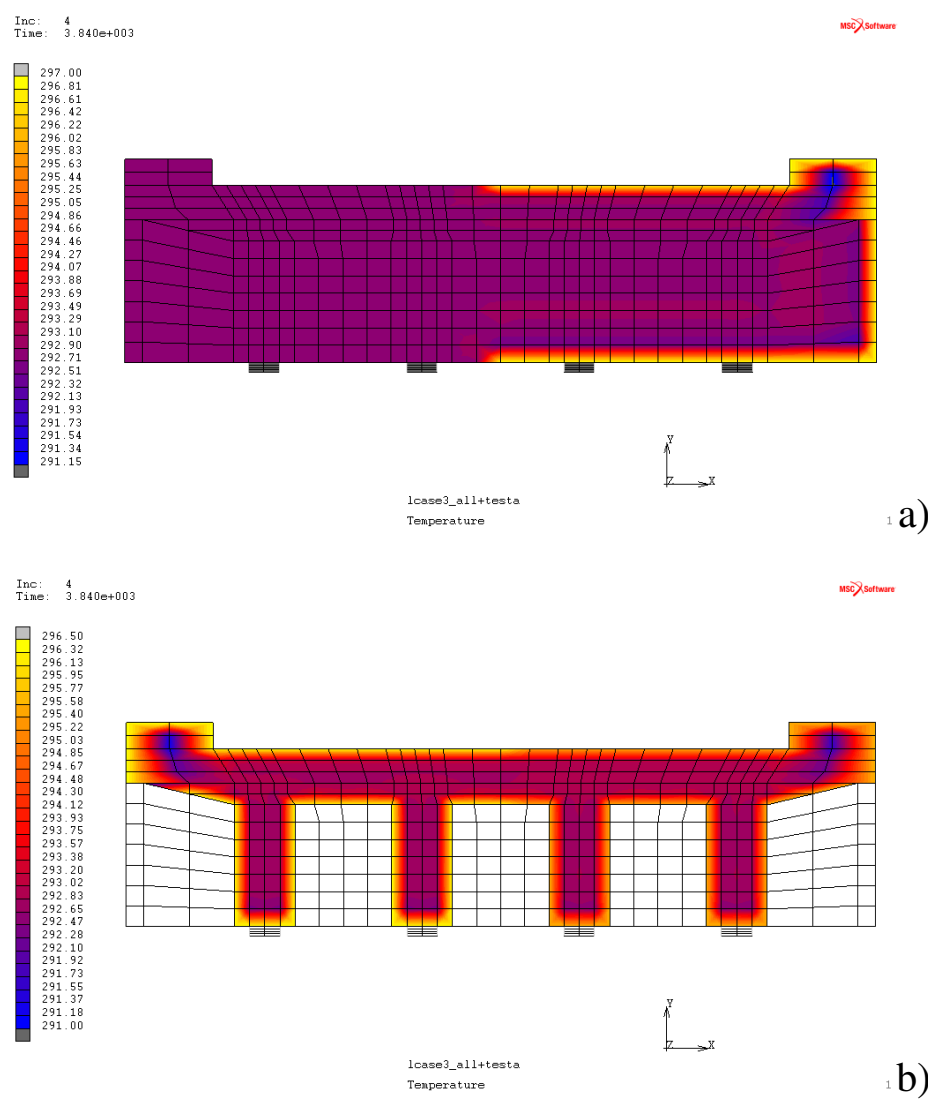

Figure 2. Temperature distribution after 1 h0ur: a) end section; b) mid-span section.

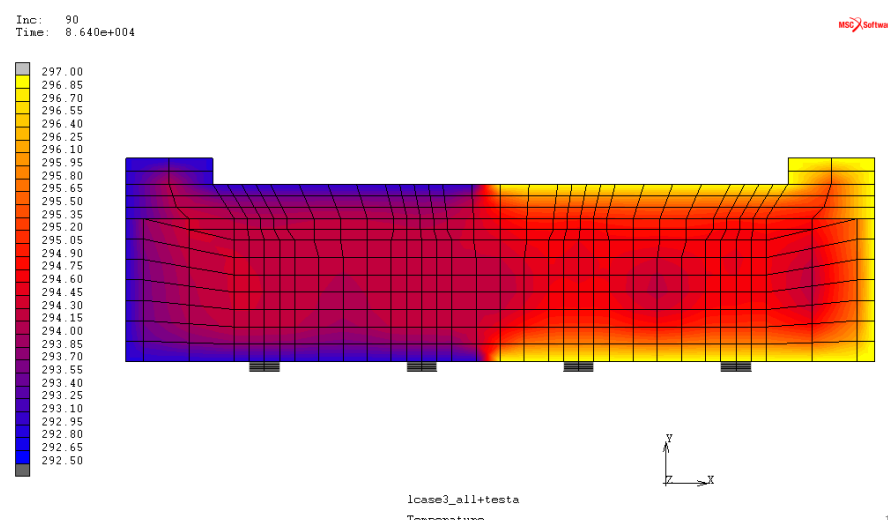

lcase3_all+testa
Tenperat ure

c)

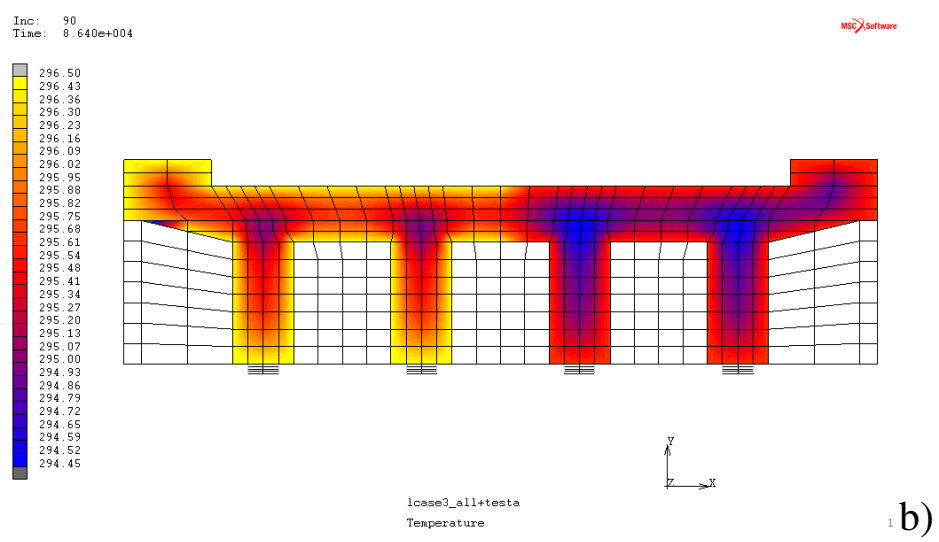

Figure 3. Temperature distribution after 1 day: a) end section; b) mid-span section. 


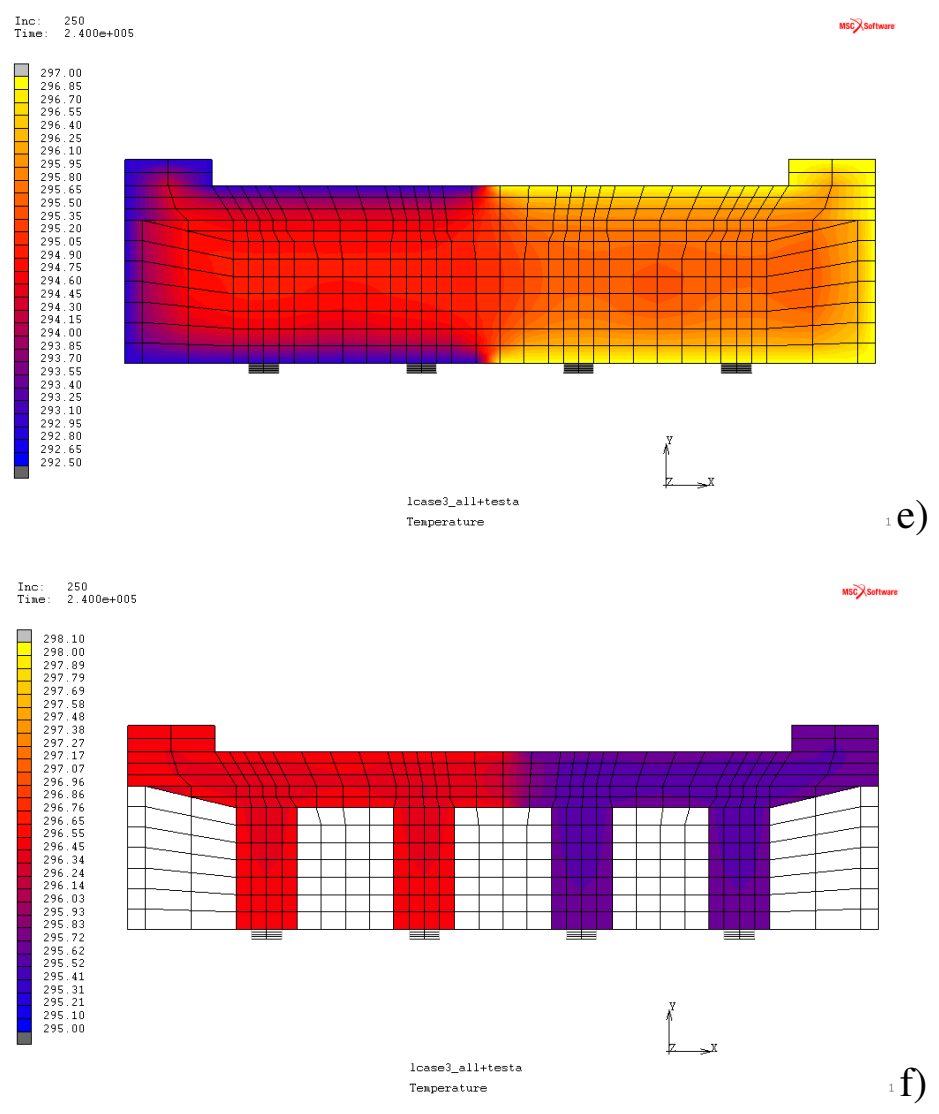

Figure 4. Temperature distribution after 3 days: a) end section; b) mid-span section.

Figure 5 provides the temperature time histories for- two central nodes of the sections considered above, namely node 4552 and 17664, respectively..

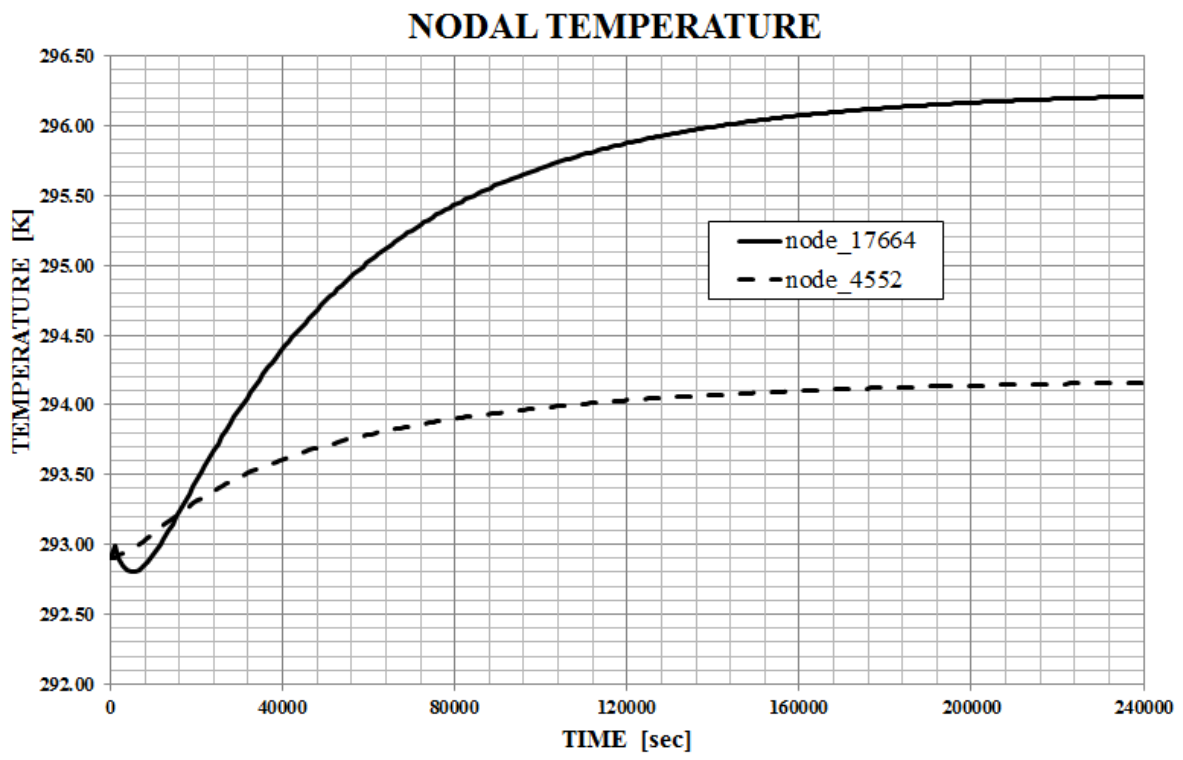

Figure 5. Temperature time histories for node 17664 (belonging to the mid-span cross section) and node 4552 (belonging to terminal cross section). 
It is seen from Figure 5 that the stationary solution is reached after 240000 seconds (i.e., nearly 3 days). It follows that the thermal inertia plays a significant role within the problem. It is worth noticing that temperature measures are taken every two hours.

\subsection{Temperature distribution on the body surface}

The preceding methodology is an operative approach to Eq. (3). But one has also to give a form to Eq. (4), which is an implicit expression of the temperature variability when moving from the top of the deck to its bottom.

Following [4] and [5] three different levels were introduced: upper deck, lateral surface and lower deck. The second level is associated with the temperature recorded by the sensor installed at the deck corner. The different temperature values for the three levels were obtained on the basis of the plot on page 59 of the book [4]:

- starting time: when the three temperature are equal each to the other;

- the lateral surface temperature follows the values read by the sensors;

- the lower deck temperature is increased, within a temporal window, from the read value;

- the upper deck temperature is increased, within a temporal window, from the read value;

In this way a representation of the actual trend is pursued. An example of the distribution of the three levels of temperature according to the partition in Figure 1, is given in Figure 6.
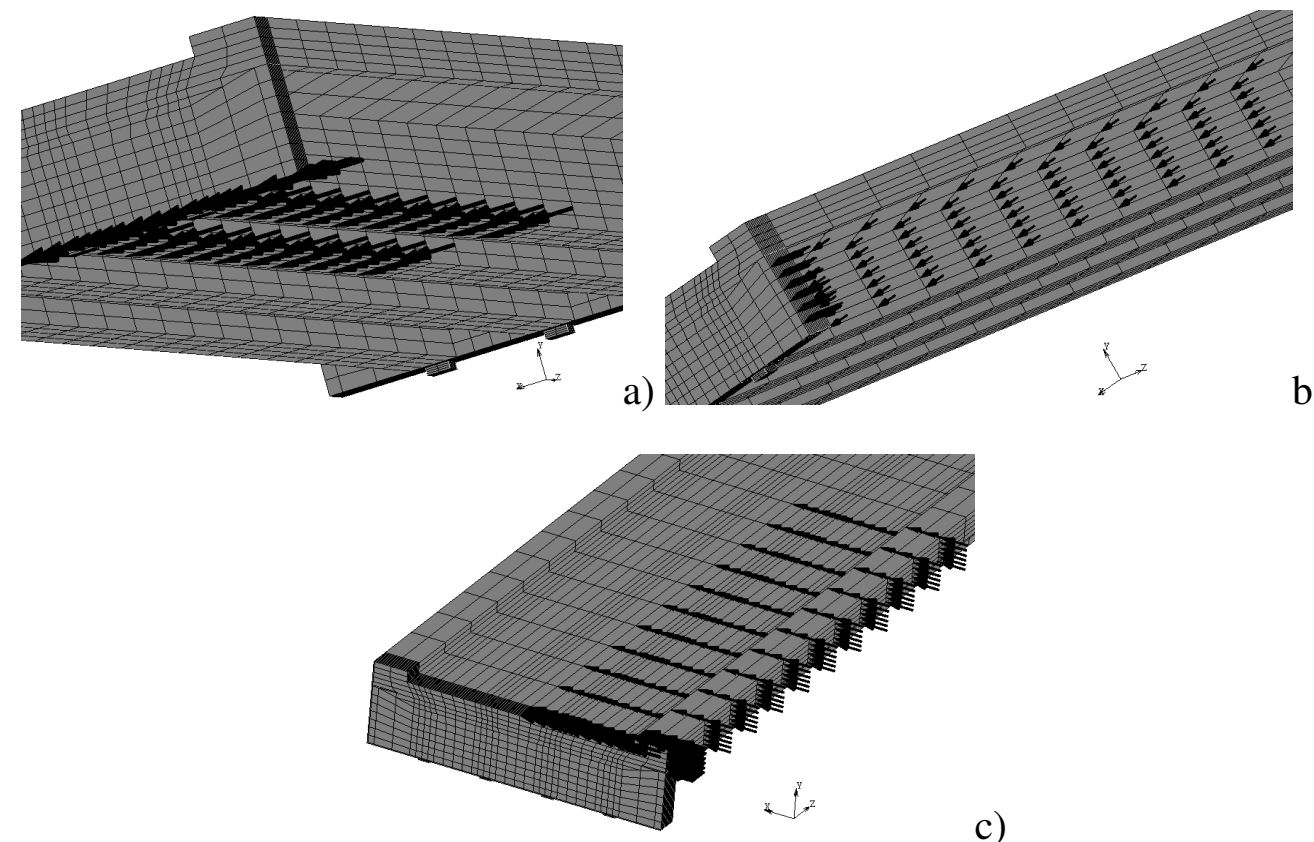

b)

c)

Figure 6. a) Lower deck distribution of temperature; b) Lateral surface distribution of temperature; c) Upper deck distribution of temperature.

\section{THE CASE STUDY}

The structural system analysed in this paper is the railway bridge called the ÖBB Brucke Großhaslau which is located in the South part of Austria. It belongs to the railway "ÖB Martinsberg - Schwarzenau", and was built in 2009-2010 to cross the road "Zwettler Straße B36" at a height of $6.70 \mathrm{~m}$. The geometry of the bridge deck is shown in Figure 7. The deck 
of the bridge consists of a single span, reinforced concrete T-beam, which supports dual-lane rail traffic. The length is $30.80 \mathrm{~m}$ and the width $8.65 \mathrm{~m}$. More details are given in [6]. Elastomeric supports under the deck are mounted and their response to temperature variations must be considered.

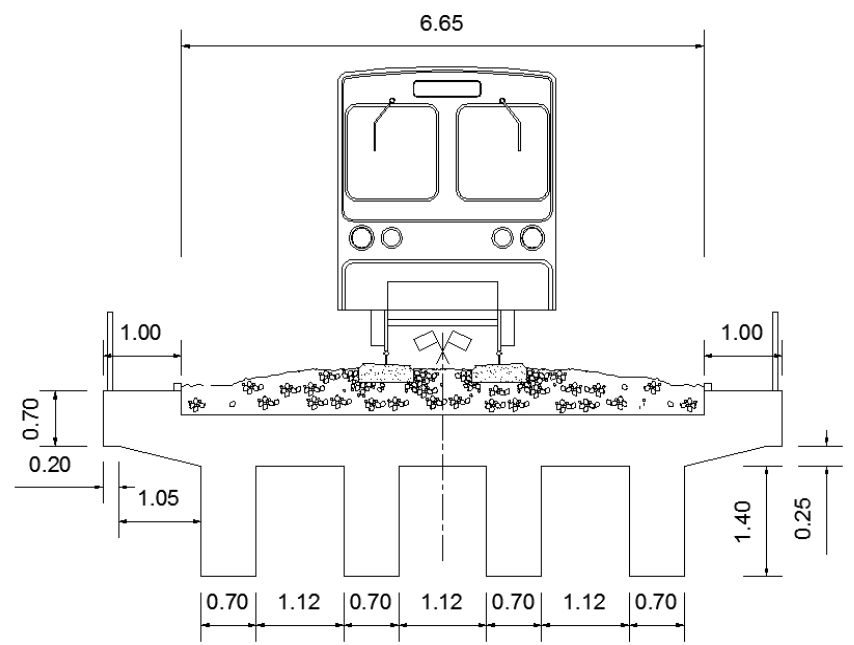

Figure 7. Transversal section of the deck for the bridge case study.

The structural health monitoring (SHM) system installed on the bridge consists of Fibre Bragg Grating (FBG) sensors [9-10]. The implemented monitoring system includes two different kinds of sensors. The first one is able to detect the variation of displacement induced by both environmental actions and train crossing events, while the second set tracks the variation of temperature. The sensors are located close to the supports. In total, ten displacement sensors and four temperature sensors were used (Figure 8). The data are recorded at different time steps (namely, every $10 \mathrm{~s}$ for the temperature values, every second for the displacement sensors and every 0.01 second for the displacement during the train crossing event), stored in a data-logger, and then sent to a PC situated in an Operation Centre. Finally, they are uploaded in a Web page were the enabled users can access them by FTP.

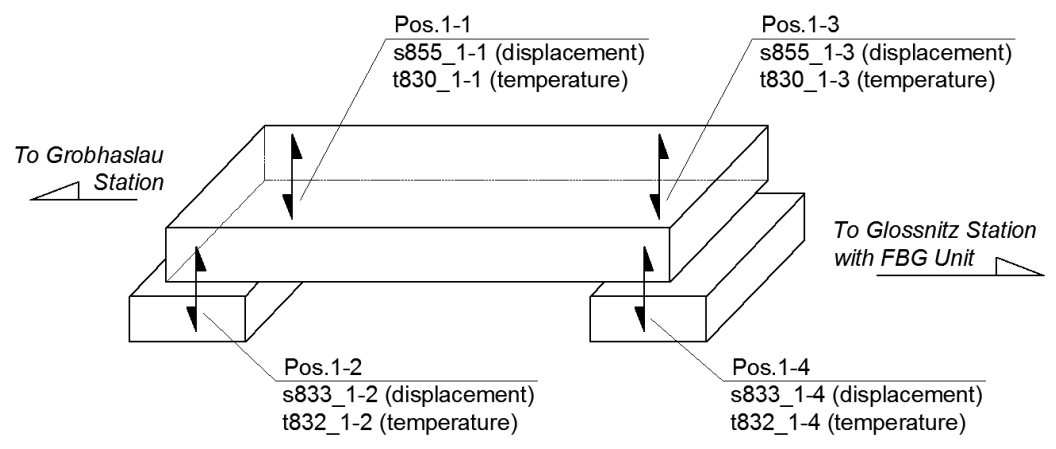

Figure 8. Position of the sensors along the bridge's deck.

Before performing the FEM modelling and analysis, all the data were managed using MatLab and Microsoft Excel. The preliminary task consists of checking the quality of the recorded data to manage gaps, zero readings from malfunctioning sensors, or obvious outliers.. Both displacements and temperature data are separately plotted against time to track their seasonal and monthly trends. As an example, Figure 9 shows the trend of the vertical displacement recorded by sensor s833_1-4 during June, 2011. More details about the data elaboration can be found in [11-12]. 


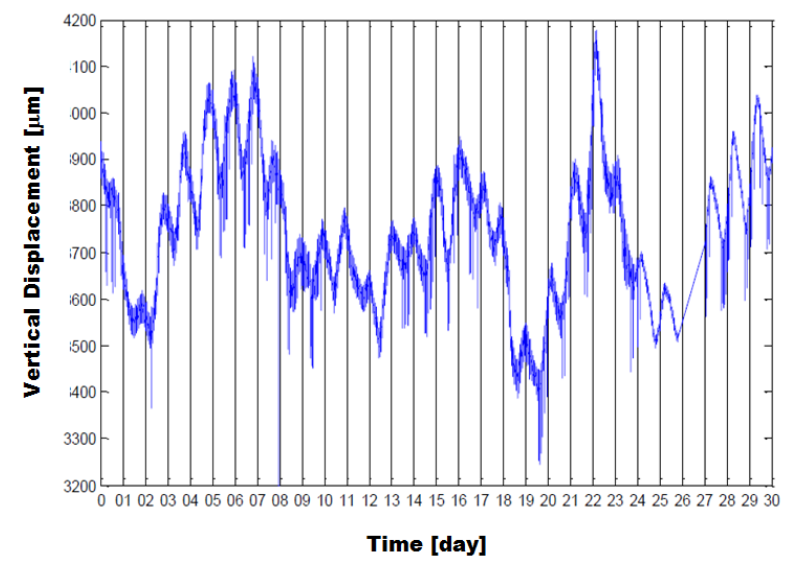

Figure 9. Trend for vertical displacements recorded by sensor s833_s1-4 - June, 2011.

\subsection{Calibration of the temperature distribution}

The 24 hours period from 12.00 of June $3^{\text {rd }}, 2011$ to 12.00 of June $4^{\text {th }} .2011$ is first considered. The temperature distribution arising from the data in [4] is summarized in Table 1.

Table 1. Temperature values (in bold) recorded by sensor $t 832 \_1-2$ from 12:00 a.m. of June $3^{\text {rd }}$ to 12:00 a.m. of June $4^{\text {th }}, 2011$ assigned to the lateral surface. Additional per cent increments provide a possible temperature distribution for upper and lower deck.

\begin{tabular}{|c|c|c|c|c|c|c|}
\hline Day & Time $[\mathrm{h}]$ & $\Theta_{\text {lower }}\left[{ }^{\circ} \mathrm{C}\right]$ & $\Theta_{\text {lateral }}\left[{ }^{\circ} \mathrm{C}\right]$ & $\Theta_{\text {upper }}\left[{ }^{\circ} \mathrm{C}\right]$ & $\begin{array}{c}\left(\Theta_{\text {lower }}-\Theta_{\text {lateral }}\right) / \Theta_{\text {lateral }} \\
{[\%]}\end{array}$ & $\begin{array}{c}\left(\Theta_{\text {upper }}-\Theta_{\text {lateral }}\right) / \Theta_{\text {latera }} \\
{[\%]}\end{array}$ \\
\hline \multirow{6}{*}{ 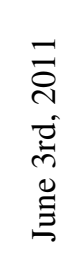 } & 12:00 & 293.4 & 292.9 & 296.9 & 0.1707 & 1.366 \\
\hline & 14:00 & 292.8 & 292.3 & 297.8 & 0.1711 & 1.881 \\
\hline & $16: 00$ & 297.4 & 296.4 & 303.4 & 0.3373 & 2.361 \\
\hline & 18:00 & 291.9 & 290.4 & 299.4 & 0.5165 & 3.099 \\
\hline & 20:00 & 287.9 & 286.7 & 293.7 & 0.4186 & 2.441 \\
\hline & 22:00 & 289.8 & 288.7 & 294.7 & 0.3810 & 2.078 \\
\hline \multirow{7}{*}{ 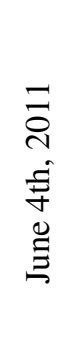 } & 0:00 & 290.1 & 289.1 & 294.6 & 0.3459 & 1.902 \\
\hline & 2:00 & 286.2 & 285.7 & 288.2 & 0.1750 & 0.875 \\
\hline & 4:00 & 286.3 & 285.8 & 287.3 & 0.1749 & 0.525 \\
\hline & $6: 00$ & 295.2 & 294.2 & 295.2 & 0.3399 & 0.3399 \\
\hline & $8: 00$ & 295.5 & 295.5 & 295.5 & 0 & 0 \\
\hline & 10:00 & 299.95 & 299.7 & 300.7 & 0.0834 & 0.3336 \\
\hline & 12:00 & 296.4 & 295.9 & 299.9 & 0.1690 & 1.352 \\
\hline
\end{tabular}

The numerical analyses carried out made evident the appropriateness of the lower curve while the upper one should be effective, and less sharping, only in the temporal window from 18.00 to 6.00. Figure 10 summarizes the adopted temperature distribution.

A basic role is played by the initial conditions which are achieved by a preliminary evolution, from a uniform temperature distribution, to the sensor readings applied to the boundary of the 4 zones of competence. Such preliminary analysis is run over a period of 8 hours, to include the thermal inertia effect. 


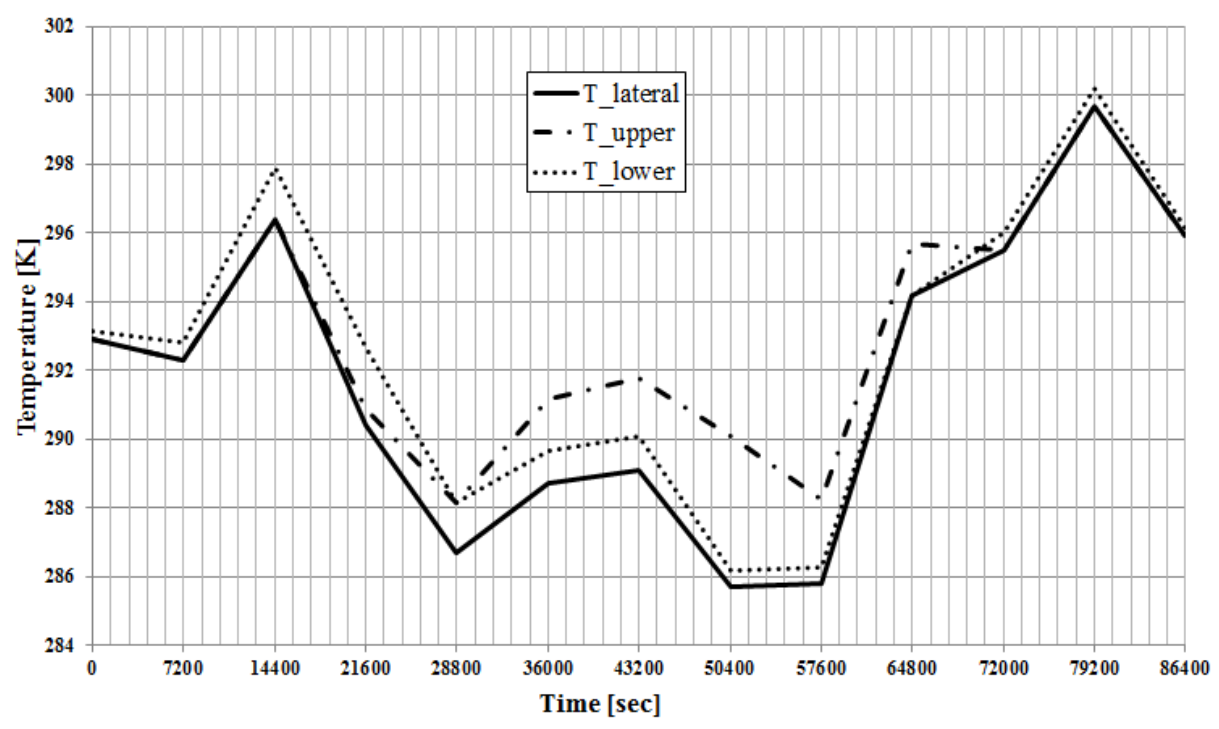

Figure 10 - Temperature recorded by sensor $t 830 \_1-1$ from 12:00 a.m. of June $3^{\text {rd }}, 2011$, to $12: 00$ a.m. of June $4^{\text {th }}$ together with the upper and lower deck temperature distributions adopted in the analysis

\subsection{Calibration of the procedure}

The thermo-mechanics properties of the materials are assigned and the period specified in the previous sub-section is adopted to calibrate the procedure. The calibration of the whole proposed procedure pursues the matching of the computed vertical displacements with the values recorded during the data acquisition. The initial conditions are assigned accounting for the thermal inertia and the boundary conditions on the temperature distribution as achieved in the previous subsection. The result in terms of absolute variation of the vertical displacement for sensor s855_s1-3 (node 8682) is represented (dotted line) in Figure 11, where it is compared with the recorded time history (continuous line).

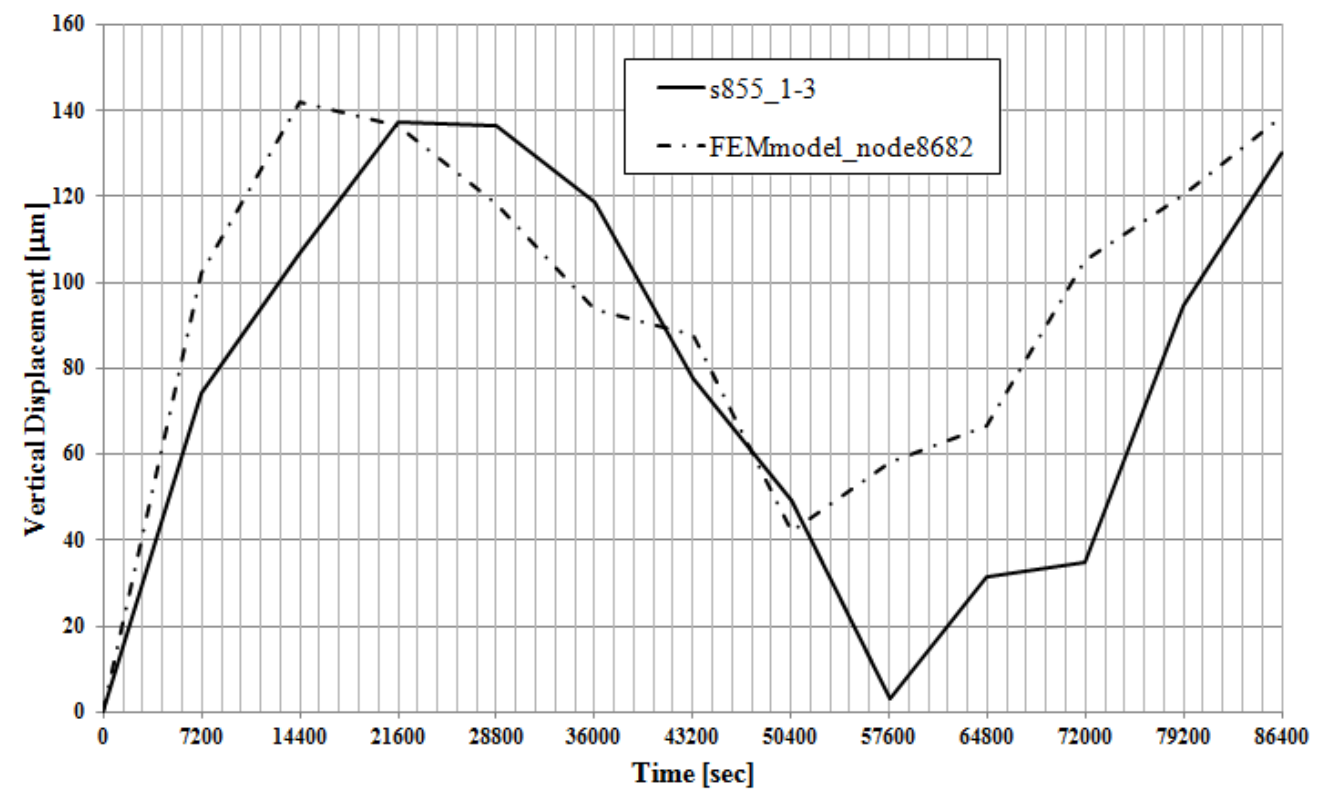

Figure 11. Absolute variation of the vertical displacement for sensor s855_s1-3 from 12:00 a.m. of June $3^{\text {rd }}, 2011$ to 12:00 a.m. of June $4^{\text {th }}$. 


\subsection{Validation of the procedure}

The procedure then tested on a different set of data: it covers the same hours of the days 14 and 15 June, 2001. The two days are selected close each to the other to avoid the influence of seasonal variations of some parameters.

The resulting time history of the absolute variation of the vertical displacement for sensor s855_s1-3 from the model (ID8682) is plotted in Figure 12 together with the measured values (continuous line).

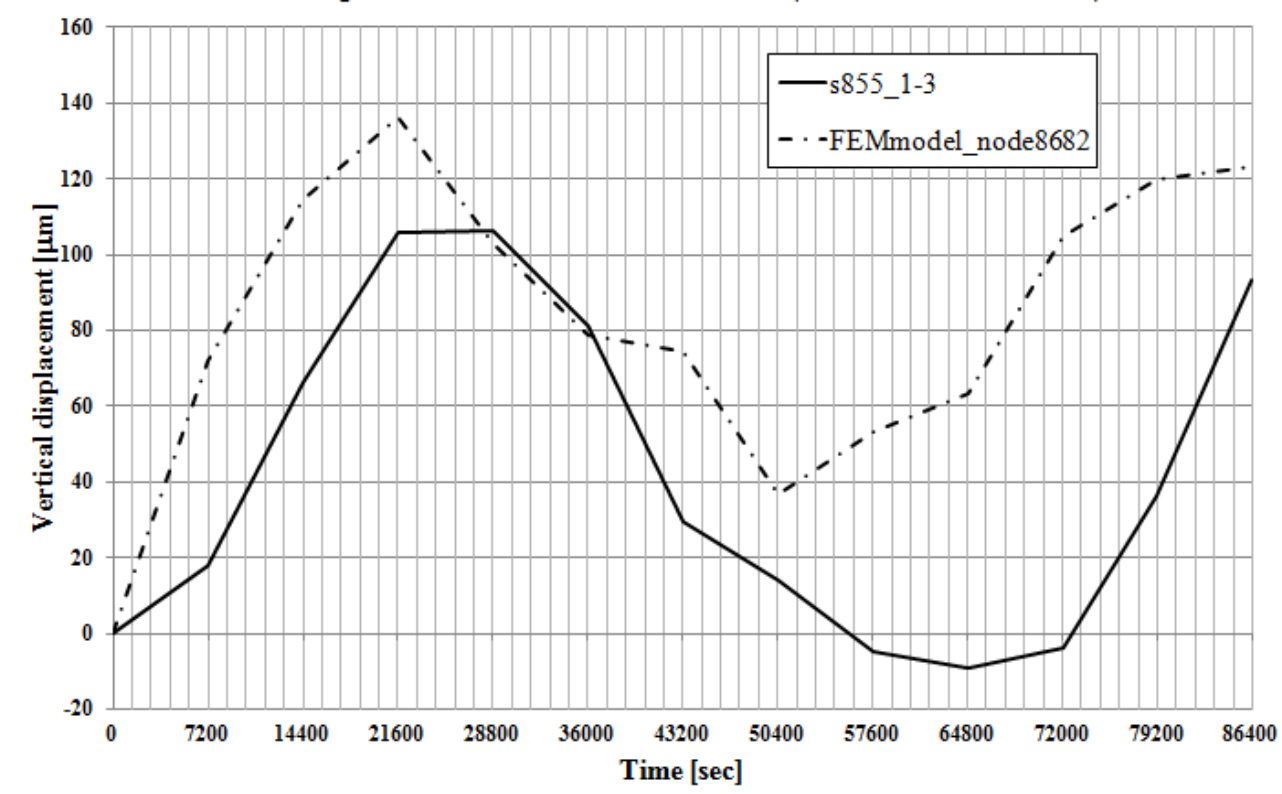

Figure 12. Absolute variation of vertical displacement for sensor s855_s1-3 from 12:00 a.m. of June $14^{\text {th }}, 2011$ to $12: 00$ a.m. of June $15^{\text {th }}$.

\section{CONCLUSIONS}

The actual temperature distribution across the deck of a bridge plays a dominant role on the estimation of the displacement field [13]. But very often only a reduced number of temperature sensors are deployed. Thus a refined study of the temperature time histories was conducted by a suitable thermo-mechanical model driven by the temperatures measured at the sensor locations. The obtained field of temperature is then used as input for a stress-strain analysis. The resulting displacements are compared with the measured one. Using a first set of data, the numerical model parameters ate calibrated, while a second set of data is used for a validation of the whole procedure.

\section{ACKNOWLEDGMENTS}

The authors are grateful to the Czech instrumentation and monitoring company Safibra for making the data available.

\section{REFERENCES}

[1] B. Peeters, G. De Roeck. One-year monitoring of the Z24-Bridge: environmental effects versus damage events, Earthquake Engineering \& Structural Dynamics, 30 (2), 149-171, 2001 . 
[2] J. Kullaa. Eliminating Environmental or Operational Influences in Structural Health Monitoring using the Missing Data Analysis, Journal Of Intelligent Material Systems And Structures, 20 (11), 1381-1390, 2009.

[3] J. Kullaa, J. Distinguishing between sensor fault, structural damage, and environmental or operational effects in structural health monitoring, Mechanical Systems And Signal Processing, 25 (8), 2976-2989, 2011.

[4] H. Wenzel and D. Pichler, Ambient Vibration Monitoring, John Wiley \& Sons, 2005.

[5] Y. Cao, J. Yim, Y. Zhao and M.L. Wang, Study of Temperature Induced Displacement for Cable Stayed Bridge Using Health Monitoring System, in F-K. Chang (ed.), Structural Health Monitoring 2009, DEStech Publications Inc., Lancaster, PA, Vol. 2, 19871994, 2009.

[6] L. Faravelli, D. Bortoluzzi, T. B.Messervey, and L. Sasek. Temperature Effects On The Response Of The Bridge "ÖBB Brucke Großhaslau". In: Proceedings of the International Conference on Advanced Dynamics and Model Based Control of Structures and Machines. Invited contribution. ABC12, Saint Petersburg, Russia, July 1-4, 2012.

[7] Marc and Mentat ${ }^{\circledR} 2010$ - Release Guide, 2010.

[8] http://www.mscsoftware.com.

[9] http://www.safibra.cz.

[10] D. Inaudi, S. Vurpillot, Monitoring of Concrete Bridges with Long-Gage Fiber Optic Sensors, Journal of Intelligent Materials Systems and Structures, 10, 280-292, 1999.

[11] B. Moro. Sistema Di Monitoraggio Per il Ponte “ÖBB Bruke Großhaslau”: effetti della temperatura, Master Degree Thesis, University of Pavia, 2012.

[12] M. Orlandoni. Simulazione Numerica Dell'effetto Della Temperatura Sul Ponte "ÖBB Bruke Großhaslau: effetti della temperatura, Master Degree Thesis, University of Pavia, 2012.

[13] H. Sohn, M. Dzwonczyk, E.G. Straser, A.S. Kiremidjian, K.H. Law and T. Meng, An Experimental Study on Temperature Effect on Modal Parameters of the Alamosa Canyon Bridge, Earthquake Engineering and Structural Dynamics, 28, 879-897, 1999. 